\title{
Immune-related genes and gene sets for predicting the response to anti-programmed death 1 therapy in patients with primary or metastatic non-small cell lung cancer
}

\author{
BOLIN CHEN $^{1}$, MIN YANG $^{2}$, KANG LI $^{1}$, JIA LI $^{1}$, LI XU $^{1}$, FANG XU $^{1}$, YAN XU $^{1}$, \\ DANDAN REN ${ }^{3}$, JIAO ZHANG ${ }^{3}$ and LIYU LIU ${ }^{1}$
}

\begin{abstract}
${ }^{1}$ Thoracic Medicine Department 2, Hunan Cancer Hospital/The Affiliated Cancer Hospital of Xiangya School of Medicine, Central South University, Changsha, Hunan 410013; ${ }^{2}$ Department of Respiratory Disease, Hunan Children's Hospital, Changsha, Hunan 410007; ${ }^{3}$ Genecast Biotechnology Co., Ltd., Beijing 100089, P.R. China
\end{abstract}

Received December 5, 2020; Accepted April 14, 2021

DOI: $10.3892 / \mathrm{ol} .2021 .12801$

\begin{abstract}
Although antibodies targeting the immune checkpoint protein programmed death-1 (PD-1) exert therapeutic effects in patients with primary or metastatic non-small cell lung cancer (NSCLC), the majority of patients exhibit partial or complete resistance to anti-PD1 treatment. Thus, the aim of the present study was to identify reliable biomarkers for predicting the response to anti-PD-1 therapy. The present study analyzed tumor specimens isolated from 24 patients (13 with primary and 11 with metastatic NSCLC) prior to treatment with approved PD1-targeting antibodies. The expression profile of 395 immune-related genes was examined using RNA immune-oncology panel sequencing. The results demonstrated that six immune-related differently expressed genes (DEGs), including HLA-F-AS1, NCF1, RORC, DMBT1, KLRF1 and IL-18, and five DEGs, including HLA-A, HLA-DPA1, TNFSF18, IFI6 and PTK7, may be used as single biomarkers for predicting the efficacy of anti-PD-1 treatment in patients with primary and with metastatic NSCLC, respectively. In addition, two DEG sets comprising either six (HLA-F-AS1, NCF1, RORC, DMBT1, KLRF and IL-18) or two (HLA-A and TNFSF18) DEGs as potential combination biomarkers for predicting the efficacy of anti-PD-1 therapy in patients with NSCLC. Patients with a calculated expression level of the DEG sets $>6.501$ (primary NSCLC) or >6.741 (metastatic NSCLC) may benefit from the anti-PD-1 therapy. Overall, these findings provided a basis for the identification of additional biomarkers for predicting the response to anti-PD-1 treatment.
\end{abstract}

Correspondence to: Dr Liyu Liu, Thoracic Medicine Department 2, Hunan Cancer Hospital/The Affiliated Cancer Hospital of Xiangya School of Medicine, Central South University, 283 Tongzipo Road, Yuelu, Changsha, Hunan 410013, P.R. China E-mail: 1ly12121212@163.com

Key words: gene set, non-small cell lung cancer, programmed death 1, biomarker

\section{Introduction}

According to global cancer statistics in 2018, lung cancer is the most commonly diagnosed cancer and the leading cause of cancer mortality, accounting for $18.4 \%$ of total cancer deaths (1). Non-small cell lung cancer (NSCLC) accounts for $80-85 \%$ of all cases of lung cancer (2). The optimal therapy for improving survival rates of NSCLC patients depends on an early diagnosis at stage I and II when surgical resection remains a feasible and consistent option (3). However, surgery is not an effective therapy for patients with an advanced or metastatic NSCLC; instead, chemotherapy, radiotherapy and targeted therapy (e.g. targeting epidermal growth factor receptor and vascular endothelial growth factor) can be used alone or in combination $(4,5)$. Monoclonal antibodies blocking immunological checkpoints, also termed immune checkpoint inhibitors (ICIs), have become promising therapeutic options for patients diagnosed with advanced NSCLC with or without metastasis (6). Among them, anti-programmed death-1 (PD-1) monoclonal antibodies have been widely used for treating advanced NSCLC (7-10). Antibodies targeting PD-1 prevent tumor cells from escaping immune-mediated destruction (11).

The PD-1 receptor is a vital immune checkpoint molecule expressed on activated $\mathrm{T}$ cells that mediates immunosuppression (12). Binding of PD-1 to its ligands (PD-L1 and PD-L2) on cancer cells suppresses $\mathrm{T}$ cells, resulting in evasion of the immune response (12). Anti-PD-1 antibodies bind to PD-1 receptors to disrupt the inhibition of $\mathrm{T}$ cells by tumor cells, enhancing the antitumor effects of the immune system (12). Previous clinical trials, including CheckMate 017 (13) and 057 (14), KEYNOTE-010(9) and KN-024 (10), have demonstrated that compared with docetaxel, anti-PD-1 antibodies significantly prolonged the overall survival and had a favorable safety profile in patients with advanced NSCLC. Despite the prominent therapeutic effects of anti-PD-1 monoclonal antibodies on patients with advanced NSCLC, only a limited fraction of patients benefit from this immunotherapeutic agent (15). Therefore, developing reliable methods to predict the efficacy of anti-PD-1 monoclonal antibody in treating patients with advanced NSCLC may provide economic relief 
for non-responding patients and save time to start other types of therapy.

At present, identification of patients with NSCLC for anti-PD-1 therapy is mainly based on the visual assessment of PD-1 expression levels in tumor tissue specimens by immunohistochemistry (IHC) (16). However, PD-1 IHC data interpretation is subjective and may be inconsistent due to a varied response to anti-PD-1 therapy in patients (17). Although a number of potential indicators for predicting response to anti-PD-1 therapy have been identified, including mutational burden (18), gut microbiome (19) and tumor-infiltrating lymphocyte abundance (20), these indicators lack sufficient sensitivity and specificity (21). Based on next-generation sequencing, gene expression profiling allows simultaneous assessment of a large number of genes and has been well used to developing response signatures for a number of types of tumor, including NSCLC (22). The sensitivity of RNA immune-oncology (IO) panel sequencing is $>20$-fold higher compared with that of whole transcriptome sequencing; specifically, RNA IO panel sequencing can detect lowly expressed coding genes with high repetition and identify differential expression with $>2$-fold changes (23). Thus, RNA IO panel sequencing provides a sensitive and accurate approach for identifying biomarkers and feature genes in clinical studies (24).

Previous studies have reported that the expression levels of PD-L1 are markedly different between primary tumors and nodal metastases in patients with advanced NSCLC $(25,26)$. In addition, the effects of anti-PD-1 antibodies differ between patients with primary and metastatic NSCLC (8). The present study aimed to investigate the roles of robust biomarkers in determining whether patients with primary or metastatic advanced NSCLC may benefit from anti-PD-1 antibody treatment.

\section{Materials and methods}

Study design. The present study was an observational study, which was conducted in accordance with the Declaration of Helsinki and approved by the Hunan Provincial Tumor Hospital (Changsha, China; approval no. 2019 fast review of scientific research [08]). All patients enrolled in the present study met the following criteria: i) They were confirmed to be affected by advanced NSCLC; ii) they received anti-PD-1 monoclonal antibody therapy as the second-line treatment; iii) they were available for a 3-year follow-up period; and iv) they signed informed consent forms. The exclusion criteria were as follows: i) Other types of tumors; ii) history of myocardial infarction, unstable angina, cerebral apoplexy or uncontrollable arrhythmias; iii) pregnancy or lactation period; iv) history of mental disorders; and v) poor compliance with the study protocol. According to these criteria, 24 patients with NSCLC were selected and enrolled in the study, including 13 patients with primary and 11 with metastatic carcinoma. Primary tumor or metastatic lymph node samples were collected from each patient by needle biopsy prior to the start of monoclonal antibody therapy and stored following formalin fixation and embedding in paraffin at room temperature. All patients were evaluated by examination of the samples and computed tomography or magnetic resonance imaging using the Response Evaluation Criteria in Solid Tumors version 1.1 (RECIST 1.1)(27). Responses to treatment were assessed every 6 weeks by computed tomography or magnetic resonance imaging using RECIST 1.1 and confirmed by a subsequent evaluation $\geq 4$ weeks from the start of treatment. Highly selective humanized monoclonal IgG4 antibodies against PD-1/PD-L1, including Nivolumab, IBI308 and Duravalumab, were administered by intravenous infusion every 2 weeks according to the treatment regimen prescribed by each patient's primary care physician. Based on the response to the anti-PD-1 treatment (28), the primary carcinoma group was subdivided into the responding $(n=7)$ and the non-responding $(n=6)$ groups. Similarly, the metastatic carcinoma group was classified into the responding $(n=5)$ and the non-responding $(n=6)$ groups. Overall survival was defined as the time between the start of treatment until death. Progression-free survival defined as the time between the start of treatment, that a patient lives with NSCLC but it does not get worse.

RNA extraction. RNA extraction was performed using the MagMAX-96 Total RNA Isolation kit (cat. no. AM1830; Invitrogen; Thermo Fisher Scientific, Inc.) according to the manufacturer's instructions. Samples were sonicated and incubated with proteinase $\mathrm{K}$ for $15 \mathrm{~min}$ at $56^{\circ} \mathrm{C}$ for protein digestion, followed by $1 \mathrm{~h}$ at $80^{\circ} \mathrm{C}$ for the disruption of nucleic acid-protein cross-links. The digested samples were centrifuged at $12,000 \mathrm{x}$ g for $5 \mathrm{~min}$ at $4^{\circ} \mathrm{C}$, and the collected supernatant was treated with DNase I. Subsequently, B1 buffer and $100 \%$ ethanol were added into the supernatant to produce the binding solution, which was transferred to a $0.45-\mu \mathrm{m}$ cellulose acetate microcentrifuge spin column and concentrated. Following washing with a washing buffer, the column was eluted with an elution buffer to collect the RNA solution. The RNA integrity number (RIN) in the RNA solution was measured using the 2100 Bioanalyzer Instrument (Agilent Technologies, Inc.). All samples had a RIN value $>7$. Finally, the RNA solution was subjected to spectrophotometric analysis for determining the A260/A280 and A260/A230 ratios. The A260/A280 ratio ranged between 1.9 and 2.1, and the A260/A230 ratio was $>2.0$.

Reverse transcription and library construction. The RNA was reverse transcribed into cDNA using the High-Capacity cDNA Reverse Transcription kit (Applied Biosystems; Thermo Fisher Scientific, Inc.) according to the manufacturer's instructions. The targeted cDNA was amplified with the multiplex immune response primer pool (included in Oncomine IO Panel; Genecast Biotechnology Co., Ltd.) targeting 395 genes. Following amplification, the amplicons were partially digested using a FuPa Reagent $\left(10 \mathrm{~min}\right.$ at $50^{\circ} \mathrm{C}, 10 \mathrm{~min}$ at $55^{\circ} \mathrm{C}, 20 \mathrm{~min}$ at $60^{\circ} \mathrm{C}$ and $60 \mathrm{~min}$ at $10^{\circ} \mathrm{C}$ ). Barcode adapters were subsequently ligated to the partially digested amplicons $(30 \mathrm{~min}$ at $22^{\circ} \mathrm{C}, 10 \mathrm{~min}$ at $72^{\circ} \mathrm{C}$ and $60 \mathrm{~min}$ at $10^{\circ} \mathrm{C}$ ). The barcode-tagged amplicons were purified and amplified. The amplified products were then dissolved in the low EDTA TE buffer for preparing the RNA library. The library concentration was determined using NanoDrop ND-1000 spectrophotometer (Thermo Fisher Scientific, Inc.), and the quality of libraries was analyzed by measuring the gene length in the library using the 2100 Bioanalyzer Instrument. 
Sequencing. Qualified RNA libraries were quantified, and the concentrations of different libraries were presented in molar concentration according to the average fragment length. All the libraries were pooled based on fragment lengths and the used chip, and sequenced on the Ion Torrent S5 platform. The sequencing kits used included Ion 540 Chef Reagents (cat. no. A27758), Ion S5 chef solutions (cat. no. A27754), Ion S5 chef supplies (cat. no. A27755), I Ion S5 sequencing reagents (cat. no. A27768) and Ion S5 Sequencing solutions (cat. no. A27767). The direction of sequencing was single-end, and the loading concentration was determined by Qubit. The nucleotide length and loading concentration of the final library are presented in Table I.

RNAIO panel sequencing and datanormalization. The RNAIO panel sequencing produced 1-2 million reads per sample. Data normalization and processing were performed as previously described (29). Briefly, $10 \mathrm{HK}$ genes were used as endogenous controls. The absolute readout of each HK gene was compared against a predetermined HK reads per million (RPM) profile. The baseline HK RPM profile was established by measuring the average RPM of 10 replicates of GM12878 cell line samples across various sequencing runs. The fold-change ratio for each HK gene was calculated as follows: Ratio of $\mathrm{HK}=$ absolute read count of HK/RPM profile of HK. The median value of all $\mathrm{HK}$ ratios was then used as the normalization ratio for each sample: Normalization ratio = Median of all HK ratios. The normalized RPM (nRPM) of all genes of each sample was calculated as: nRPM (sample $S$, gene $G$ ) = Absolute read count (sample $S$, gene $G$ )/Normalization ratio (sample $S$ ).

Data analysis. The sequencing data were subjected to quality control according to the following standards: Mapped reads $\geq 200,000$; number of detected $\mathrm{HK}$ genes $\geq 6$; and valid reads (on-target ratio) $\geq 67 \%$. The sequencing quality control data of all patients are presented in Table II. The gene expression levels in the qualified samples were quantified and normalized as follows: Firstly, the RPM value of HK genes in each sample was divided by the standard HK gene value to generate a raw value, and the values of all samples were calculated accordingly; secondly, the median of all the values of samples was presented as the normalized value; finally, the RPM of each sample was divided by the normalized value to produce the corresponding nRPM. An R/Bioconductor software package 'limma' (30) running on the R 3.5.3 software (31) was used to perform differential expression analysis according to the $\log _{2}(\mathrm{nRPM}+1)$ value. The DEGs were determined using the 'limma' package with a false discovery rate of 0.05 and absolute fold-change $\geq 2$. The enrichment analysis of DEGs was performed using the 'ClusterProfiler' package (32), including Gene Ontology (GO; molecular function, biological process and cellular component; http://geneontology.org), Kyoto Encyclopedia of Genes and Genomes Pathway (KEGG; https://www.genome.jp/kegg) database and Reactome Pathway Database (https://reactome. org), to determine the primary functions of the DEGs as well as the associated metabolic and signaling pathways. Subsequently, differential analysis of gene sets was performed using the gene set variation analysis (GSVA) package for $\mathrm{R}$ (33). A receiver operating characteristic (ROC) curve of the DEG set was used to calculate the cut-off values.
Table I. Type of sequencing and loading concentration of the final library.

\begin{tabular}{|c|c|c|}
\hline Sample no. & $\begin{array}{l}\text { Nucleotide } \\
\text { length, bp }\end{array}$ & $\begin{array}{l}\text { Loading concentration of } \\
\text { the final library, pM }\end{array}$ \\
\hline 201600596 & 204 & $45,177.3$ \\
\hline 201526397 & 202 & $66,084.3$ \\
\hline 201509607 & 202 & $18,998.1$ \\
\hline 201517774 & 203 & $54,449.1$ \\
\hline 201518131 & 201 & $56,903.4$ \\
\hline 201600702 & 198 & $40,450.5$ \\
\hline 201723630 & 201 & $59,812.2$ \\
\hline 201614107 & 202 & $25,179.3$ \\
\hline 201811713 & 200 & $46,904.4$ \\
\hline 201726177 & 199 & $60,266.7$ \\
\hline 201726775 & 201 & 5,9085 \\
\hline 201619238 & 201 & $32,269.5$ \\
\hline 201613253 & 199 & $57,630.6$ \\
\hline 201729934 & 200 & $53,358.3$ \\
\hline 201729044 & 200 & $66,811.5$ \\
\hline 20180193 & 204 & $44,541.0$ \\
\hline 201817287 & 201 & $51,176.7$ \\
\hline 201814975 & 195 & $57,994.2$ \\
\hline 201811594 & 200 & $50,813.1$ \\
\hline 201800133 & 200 & $48,904.2$ \\
\hline 201801858 & 200 & $56,085.3$ \\
\hline 201703656 & 204 & $67,902.3$ \\
\hline 201715487 & 200 & $42,177.6$ \\
\hline 201816274 & 200 & $41,450.4$ \\
\hline
\end{tabular}

Statistical analysis. Data are presented as the mean \pm standard deviation. Data were analyzed by SPSS 20.0 (IBM Corp.) and R 3.5.3 software. The expression level of the DEG set for each patient was calculated by the mean of $\log _{2}(n R P M+1)$ values. The mean value was calculated by summing the four upregulated gene expression values, subtracting the two downregulated gene expression values and by dividing the result by 6 . The survival analysis for various groups was performed using the Kaplan-Meier survival analysis with the log-rank test. Fisher's exact test was used for the analysis of patient characteristics. Mann-Whitney U test was used to assess the DEG expression levels in the responding and non-responding groups. $\mathrm{P}<0.05$ was considered to indicate a statistically significant difference.

\section{Results}

Associations between clinicopathological features and the efficacy of anti-PD-1 monoclonal antibody treatment. The present study performed the RNA IO panel sequencing on samples form 24 patients with NSCLC prior to anti-PD-1 therapy. Following therapy, all 24 patients were divided into the responding (partial response or stable disease; $n=7$ primary and 5 metastatic cancer cases) and non-responding (progressive disease; $n=6$ primary and 6 metastatic cancer cases) groups based on a previously reported response pattern (28). As 
Table II. The sequencing quality control result of all the patients.

\begin{tabular}{|c|c|c|c|c|c|c|}
\hline Sample no. & Mapped reads, $\mathrm{n}$ & On target reads, $\mathrm{n}$ & Valid reads & Detected genes, $\mathrm{n}$ & HK genes, $n$ & QC result \\
\hline 201600596 & $2,250,344$ & $1,928,995$ & $86 \%$ & 362 & 10 & Pass \\
\hline 201526397 & $2,072,309$ & $1,830,263$ & $88 \%$ & 361 & 10 & Pass \\
\hline 201509607 & $2,215,655$ & $2,040,175$ & $92 \%$ & 353 & 10 & Pass \\
\hline 201517774 & $2,538,679$ & $2,367,826$ & $93 \%$ & 380 & 10 & Pass \\
\hline 201518131 & $2,710,910$ & $2,464,217$ & $91 \%$ & 376 & 10 & Pass \\
\hline 201600702 & $2,793,598$ & $2,578,212$ & $92 \%$ & 376 & 10 & Pass \\
\hline 201723630 & $2,068,023$ & $1,888,519$ & $91 \%$ & 366 & 10 & Pass \\
\hline 201614107 & $2,270,331$ & $2,074,856$ & $91 \%$ & 358 & 10 & Pass \\
\hline 201811713 & $2,498,210$ & $2,260,380$ & $90 \%$ & 369 & 10 & Pass \\
\hline 201726177 & $2,367,111$ & $2,152,414$ & $91 \%$ & 360 & 10 & Pass \\
\hline 201726775 & $1,085,151$ & 950,267 & $88 \%$ & 357 & 10 & Pass \\
\hline 201619238 & $2,049,446$ & $1,837,943$ & $90 \%$ & 350 & 10 & Pass \\
\hline 201613253 & $2,444,755$ & $2,256,998$ & $92 \%$ & 361 & 10 & Pass \\
\hline 201729934 & $2,597,198$ & $2,342,932$ & $90 \%$ & 360 & 10 & Pass \\
\hline 201729044 & $2,107,692$ & $1,897,977$ & $90 \%$ & 365 & 10 & Pass \\
\hline 20180193 & $2,414,549$ & $2,192,169$ & $91 \%$ & 369 & 10 & Pass \\
\hline 201817287 & $2,358,980$ & $2,077,554$ & $88 \%$ & 364 & 10 & Pass \\
\hline 201814975 & $2,240,242$ & $2,056,542$ & $92 \%$ & 373 & 10 & Pass \\
\hline 201811594 & $2,371,493$ & $2,164,936$ & $91 \%$ & 356 & 10 & Pass \\
\hline 201800133 & $2,427,701$ & $2,202,896$ & $91 \%$ & 365 & 10 & Pass \\
\hline 201801858 & $2,461,863$ & $2,186,381$ & $89 \%$ & 364 & 10 & Pass \\
\hline 201703656 & $2,116,778$ & $1,929,443$ & $91 \%$ & 368 & 10 & Pass \\
\hline 201715487 & $2,359,914$ & $2,189,056$ & $93 \%$ & 369 & 10 & Pass \\
\hline 201816274 & $2,339,855$ & $2,138,627$ & $91 \%$ & 361 & 10 & Pass \\
\hline
\end{tabular}

HK, housekeeping; QC, quality control.

illustrated in Table III, there were no significant differences in the age, sex, pathological diagnosis, clinical stage, therapeutic regimens and history of smoking between the responding and non-responding groups $(\mathrm{P}>0.05)$. These results suggested that the assessed clinicopathological features were not associated with the efficacy of anti-PD-1 therapy in these patients.

Identification of DEGs between the responding and non-responding groups of patients with NSCLC. The gene expression levels in tumor tissues were analyzed and compared between the responding and non-responding groups of patients with NSCLC patients. As demonstrated in Fig. 1A and B, six genes were identified as significant DEGs between the responding and non-responding groups of patients with primary NSCLC; among them, four were upregulated and two were downregulated in the responding group compared with the non-responding group. Furthermore, the heatmap of DEGs revealed the downregulation of the levels of HLA-F antisense RNA 1 (HLA-F-AS1) and neutrophil cytosolic factor 1 (NCF1), involved in autoimmune diseases, as well as the upregulation of the levels of transcription factor RAR-related orphan receptor $\mathrm{C}$ (RORC), deleted in malignant brain tumors 1 (DMBT1), involved in the interaction between the tumor cells and immune system, killer cell lectin-like receptor F1 (KLRF1) and interleukin-18 (IL-18) in the responding group compared with those in the non-responding group (Fig. 1C).
The gene expression analysis also identified major histocompatibility complex class IA (HLA-A), major histocompatibility complex class II DP $\alpha 1$ (HLA-DPA1), tumor necrosis factor ligand superfamily member 18 (TNFSF18), interferon $\alpha$-inducible protein 6 (IFI6) and inactive tyrosine-protein kinase 7 (PTK7) as DEGs between the responding and non-responding patients with metastatic NSCLC (Fig. 1D and E). As demonstrated in the heatmap in Fig. 1F, the expression levels all five DEGs were upregulated in the responding group compared with those in the non-responding group.

Enrichment of DEGs in patients with primary or metastatic NSCLC. Functional enrichment analysis of the six DEGs in patients with primary NSCLC was next performed. As presented in Fig. 2, the six DEGs were significantly enriched in the 'phosphatidylinositol 3-kinase signaling', 'T-helper cell differentiation', 'phosphatidylinositol-mediated signaling' and 'antigen processing-cross presentation' signaling pathways. Similarly, the significantly enriched signaling pathways of the five DEGs in patients with metastatic NSCLC mainly included 'interferon signaling', 'cytokine signaling in immune system', 'antigen processing and presentation of exogenous peptide antigen', 'antigen binding' and 'interferon-gamma-mediated pathway’ (Fig. 3). 
Table III. Clinicopathological features of all patients with NSCLC.

\begin{tabular}{|c|c|c|c|c|c|c|}
\hline \multirow[b]{2}{*}{ Characteristic } & \multicolumn{3}{|c|}{ Primary NSCLC $(n=13)$} & \multicolumn{3}{|c|}{ metastatic NSCLC $(n=11)$} \\
\hline & $\begin{array}{c}\text { Responding } \\
\quad(\mathrm{n}=7)\end{array}$ & $\begin{array}{l}\text { Non-responding } \\
\quad(\mathrm{n}=6)\end{array}$ & P-value & $\begin{array}{c}\text { Responding } \\
(\mathrm{n}=5)\end{array}$ & $\begin{array}{l}\text { Non-responding } \\
\quad(\mathrm{n}=6)\end{array}$ & P-value \\
\hline Age, years & 54.25 & 52.79 & & 58.73 & 53.83 & \\
\hline \multicolumn{7}{|l|}{ Sex, n } \\
\hline Male & 7 & 5 & 0.462 & 5 & 5 & $>0.999$ \\
\hline Female & 0 & 1 & & 0 & 1 & \\
\hline \multicolumn{7}{|l|}{ Disease stage, $\mathrm{n}$} \\
\hline III B & 1 & 0 & $>0.999$ & 0 & 0 & NA \\
\hline IV & 6 & 6 & & 5 & 6 & \\
\hline \multicolumn{7}{|l|}{ Pathological diagnosis, $\mathrm{n}$} \\
\hline Adenocarcinoma & 4 & 2 & 0.592 & 3 & 4 & 0.592 \\
\hline Squamous cell carcinoma & 3 & 4 & & 2 & 2 & \\
\hline \multicolumn{7}{|l|}{ Therapeutic regimen, $\mathrm{n}$} \\
\hline Duravalumab & 4 & 1 & 0.266 & 3 & 1 & 0.437 \\
\hline IBI308 & 0 & 1 & & 1 & 1 & \\
\hline Nivolumab & 3 & 4 & & 1 & 4 & \\
\hline \multicolumn{7}{|l|}{ History of smoking, $\mathrm{n}$} \\
\hline No & 6 & 2 & 0.103 & 2 & 5 & 0.242 \\
\hline Yes & 1 & 4 & & 3 & 1 & \\
\hline
\end{tabular}

NSCLC, non-small cell lung cancer.
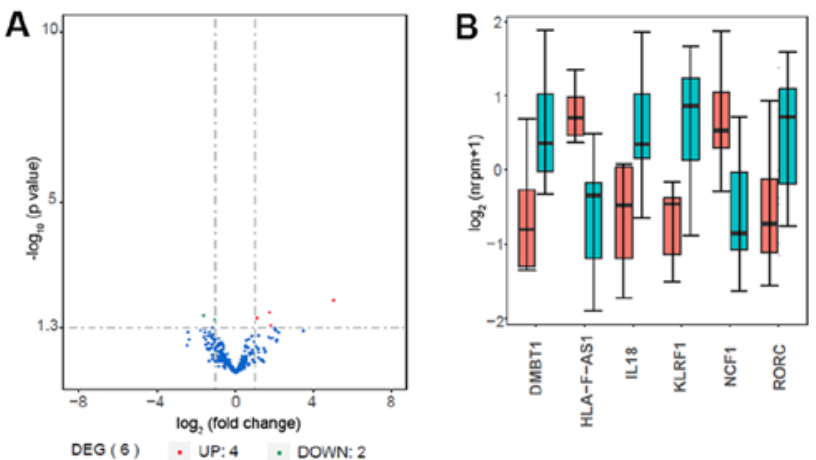

C

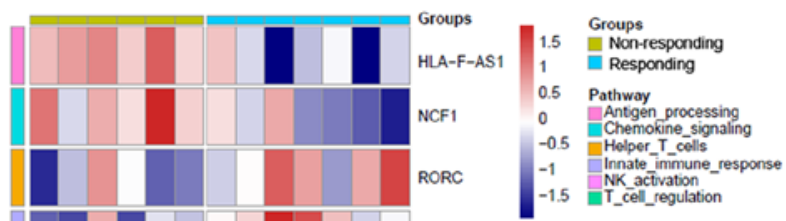

Responding group vs. Non-responding group
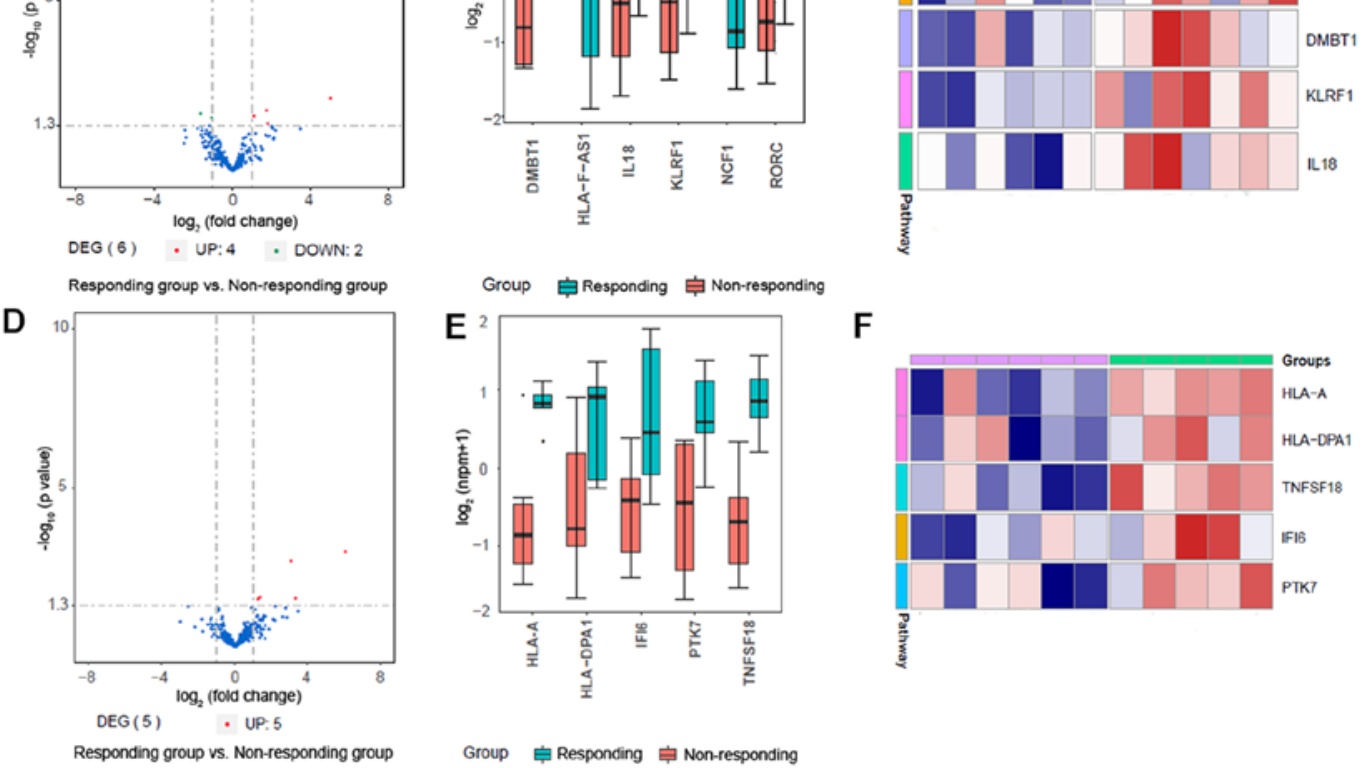

$\mathbf{F}$

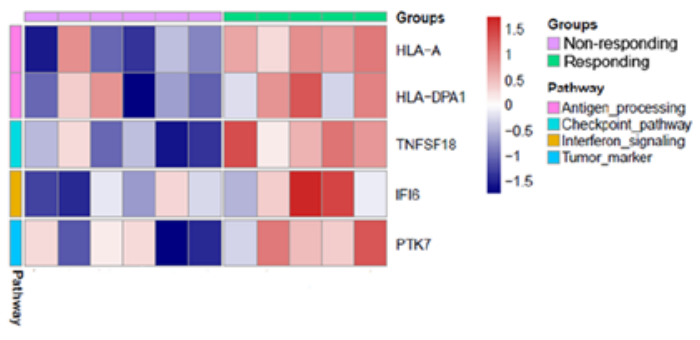

Figure 1. Effective gene expression map of tumor tissues from the responding and non-responding groups. (A) Volcano plot of DEGs in patients with primary NSCLC. (B) Box plot of DEG expression levels in patients with primary NSCLC. (C) The expression levels of DEGs associated with various pathways in patients with primary NSCLC. (D) volcano map in patients with metastatic NSCLC. (E) Box plot of DEG expression levels in patients with metastatic NSCLC. (F) The expression levels of DEGs associated with various pathways in patients with metastatic NSCLC. NSCLC, non-small cell lung cancer; DEG, differentially expressed gene; HLA-F-AS1, HLA-F antisense RNA 1; NCF1, neutrophil cytosolic factor 1; RORC, RAR-related orphan receptor C; DMBT1, deleted in malignant brain tumors 1; KLRF1, killer cell lectin-like receptor F1; IL-18, interleukin-18; HLA-A, major histocompatibility complex class IA; HLA-DPA1, major histocompatibility complex class II DP $\alpha 1$; TNFSF18, tumor necrosis factor ligand superfamily member 18; IFI6, interferon $\alpha$-inducible protein 6; PTK7, inactive tyrosine-protein kinase 7. 

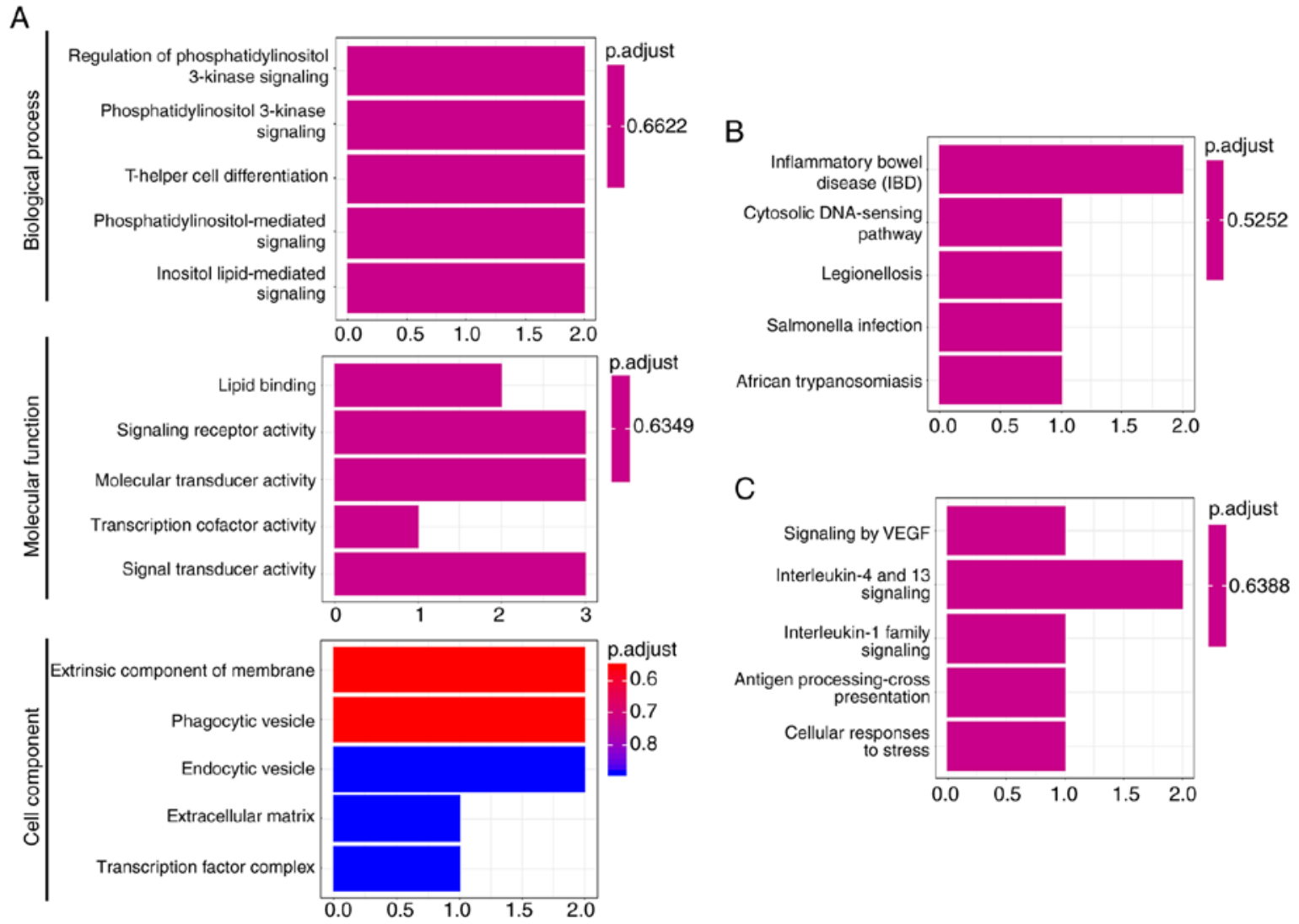

Figure 2. Enrichment analysis of six differentially expressed genes from patients with primary non-small cell lung cancer. (A) Gene Ontology analysis, including biological process, cell component and molecular function. (B) Kyoto Encyclopedia of Genes and Genomes pathway analysis. (C) Reactome enrichment analysis.
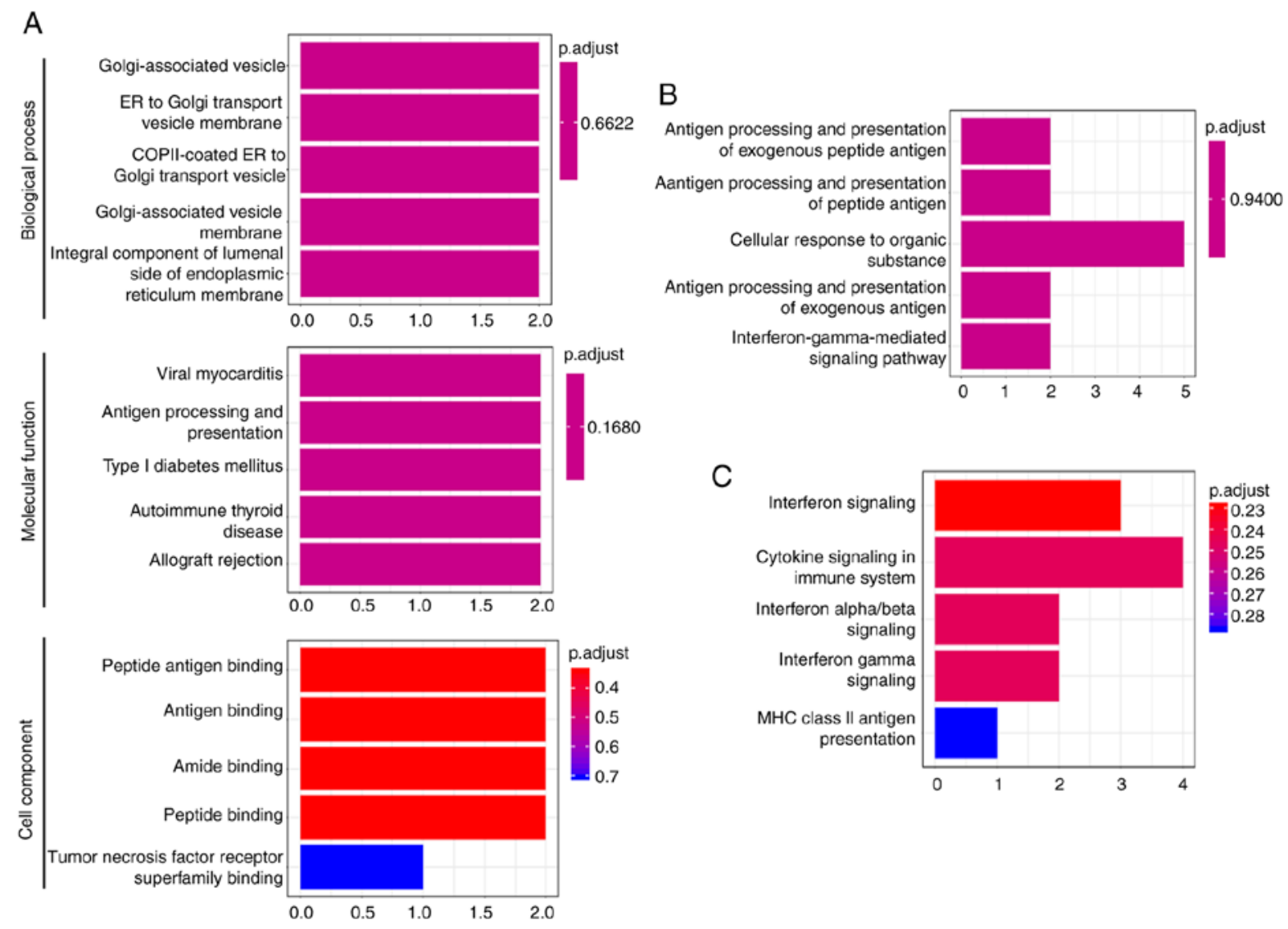

Figure 3. Enrichment analysis of five DEGs in patients with metastatic NSCLC. (A) Gene Ontology analysis, including biological process, cellular component and molecular function. (B) Kyoto Encyclopedia of Genes and Genomes analysis. (C) Reactome enrichment analysis. 
A

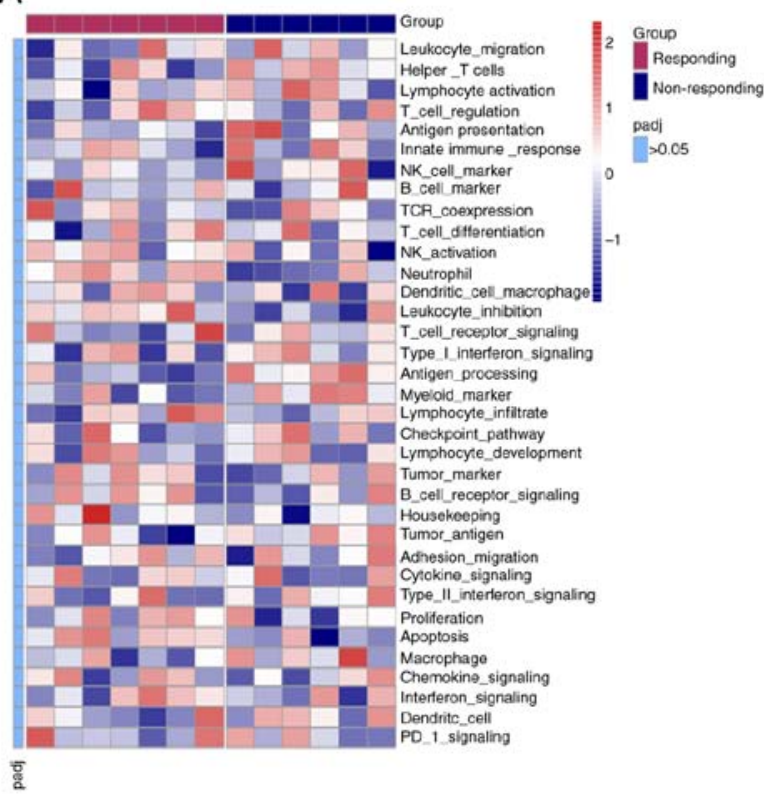

B

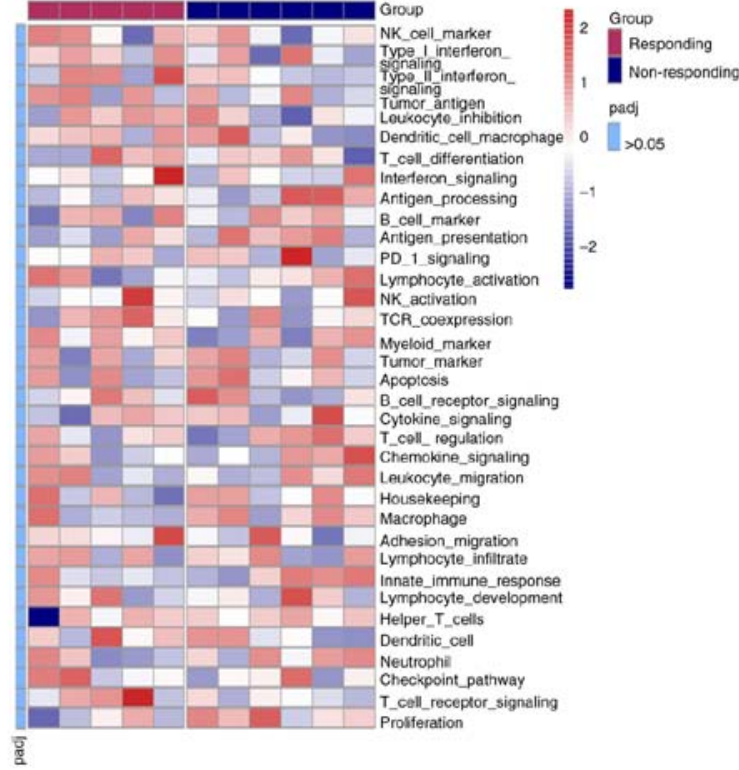

Figure 4. Associations between DEGs and PFS. (A) Associations between DEGs and PFS in patients with primary NSCLC. (B) Associations between DEGs and PFS in patients with metastatic NSCLC. DEGs, differentially expressed genes; PFS, progression-free survival; NSCLC, non-small cell lung cancer.

When all 395 analyzed genes in patients with primary or metastatic NSCLC were subjected to cluster analysis of 35 immune-related signaling/functional pathways using GSVA, the results demonstrated that there were no significant differences in any of these pathways between the responding and non-responding groups (adjusted $\mathrm{P}>0.05$; Fig. 4 ).

DEG set-based prediction of the efficacy of anti-PD-1 therapy in patients with primary NSCLC. Cluster analysis of the six DEGs in 13 patients with primary NSCLC was further performed (Fig. 5A). Although the results of one patient deviated from the others, the remaining patients had the correct attribution and could be distinguished, suggesting that the gene set composed by these six DEGs could fairly distinguish the patients between the responding and non-responding groups. Therefore, the present study sought to determine whether the six DEGs may form a DEG set for predicting the effect of anti-PD-1 treatment in these patients. As illustrated in Fig. 5B, the expression levels of the DEG set in the responding group were significantly higher compared with those in the non-responding group $(\mathrm{P}=0.011)$. Subsequently, the ROC curve was used to determine the cut-off value indicating the efficacy of anti-PD-1 treatment. The expression level of the DEG set exhibited statistical significance in predicting the efficacy of anti-PD-1 treatment [area under the curve $(\mathrm{AUC})=0.881$; $\mathrm{P}=0.022$; sensitivity, $100 \%$; specificity, $83.3 \%$; Fig. 5C). Based on the calculated cut-off value, patients with an expression level of the DEG set $>6.501$ benefited from anti-PD-1 therapy.

DEG set-based prediction of the efficacy of anti-PD-1 treatment in patients with metastatic NSCLC. Cluster analysis of the five DEGs in patients with metastatic NSCLC was subsequently performed (Fig. 6A). The results demonstrated that the set of five DEGs did not fully distinguish between patients in the responding and non-responding groups. Therefore, cluster analysis was performed on subsets of the 5 DEGs. As presented in Fig. 6B, the DEG set comprising HLA-A and TNFSF18 effectively distinguished the two groups of patients. The expression level of the gene set was calculated by the mean of $\log _{2}(n R P M+1)$ values. Notably, the responding group displayed a significantly higher expression levels of the DEG set compared with those in the non-responding group $(\mathrm{P}=0.004$; Fig. 6C). As indicated by the cut-off value (Fig. 6D), the expression level of the gene set had statistical significance in predicting the efficacy of anti-PD-1 monoclonal antibody treatment $(\mathrm{AUC}=0.967 ; \mathrm{P}=0.011$; sensitivity, $100 \%$; specificity, $83.3 \%$ ); patients with an expression level of the DEG set $>6.741$ benefited from anti-PD-1 antibody therapy.

Associations between DEGs and progression-free survival (PFS). Lastly, the present study conducted survival analysis on 13 patients with primary carcinoma and 10 patients with metastatic carcinoma. As demonstrated in Fig. 7A, in the primary carcinoma group, patients with a longer PFS exhibited higher expression levels of DMBT1, KLRF1, RORC and the 6-gene set compared with those in patients with a shorter PFS. Similarly, in the metastatic carcinoma group, patients with a longer PFS displayed higher expression levels of HLA-A, TNFSF18 and the 2-gene set compared with those in patients with a shorter PFS (Fig. 7B).

\section{Discussion}

Since surgery is ineffective for patients with advanced NSCLC, chemotherapy remains the preferred treatment option (34). Anti-PD-1 monoclonal antibody, an immune checkpoint inhibitor, has provided a breakthrough in the treatment of patients with advanced NSCLC (35). The role of anti-PD-1 antibodies in the first- and second-line treatment of NSCLC or in the local adjuvant therapy of NSCLC has been established in previous studies (36-38). However, the effectiveness 
A
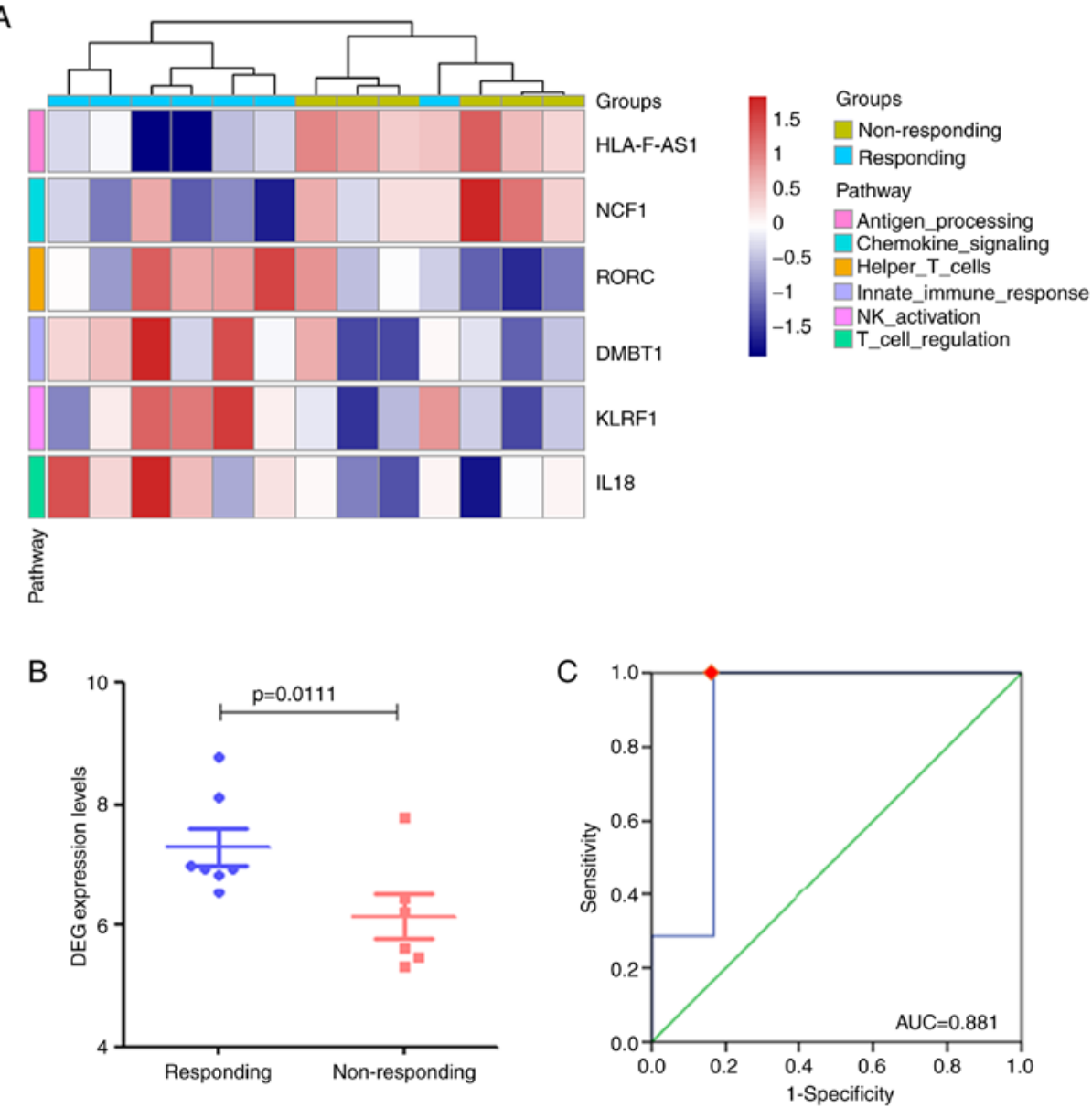

Figure 5. DEG set-based prediction of the efficacy of anti-PD-1 treatment in patients with primary NSCLC. (A) Cluster analysis of the six DEGs identified in patients with primary NSCLC. (B) The expression levels of the DEG set in the responding group were significantly higher compared with those in the non-responding group. (C) Receiver operating characteristic curve was used to predict the efficacy of anti-PD-1 treatment. Patients with a DEG set expression value $>6.501$ benefited from anti-PD-1 therapy. PD-1, programmed death-1; NSCLC, non-small cell lung cancer; DEG, differentially expressed gene; AUC, area under the curve.

of anti-PD-1 therapy on tumors is limited, and rapid growth of tumors is observed in a number of patients (35). The high cost and difficulty in predicting the efficacy have become the bottleneck for the promotion of anti-PD-1 therapy (39). Thus, there is an urgent need to identify efficient and precise biomarkers for screening patients with NSCLC that may respond to anti-PD-1 antibody therapy. Analysis of the functional mechanism of anti-PD-1 monoclonal antibody suggests that immune-related genes and pathways serve an important role in its antitumor effect (40). In the present study, RNA IO panel sequencing was used to examine the expression levels of 395 genes associated with immune pathways in patients with primary or metastatic NSCLC prior to the standard anti-PD-1 antibody therapy (41). Literature review and data analysis revealed that five immune-related genes and two gene sets may potentially be used for predicting the therapeutic effects of PD-1 inhibitors in patients with primary or metastatic NSCLC.

In the present study, among patients with primary NSCLC, the responding group exhibited lower expression levels of HLA-F-AS1 and NCF1 compared with those in the non-responding group. HLA-F-AS1 is a long non-coding RNA that is significantly downregulated in human lung adenocarcinoma tissues compared with matched adjacent non-tumor tissues (42). The NCF1 protein is an essential component of the phagocytic NADPH oxidase type 2, which is involved in autoimmune inflammatory disorders (43). Kelkka et al (44) have reported that mice lacking NCF1 developed markedly fewer Lewis lung carcinoma tumors compared with those in the wild-type controls. Consistently, the results of the present study demonstrated that patients with primary NSCLC with a longer PFS exhibited higher expression levels of HLAF-AS1 and NCF1 compared with those in patients with a shorter PFS. Thus, low levels of HLA-F-AS1 and NCF1 may be biomarkers for predicting response of patients with primary NSCLC to anti-PD-1 therapy. In addition, low expression levels of HLA-F-AS1 may indicate improved efficacy of anti-PD-1 treatment $(45,46)$. DMBT1 has been proposed as a candidate tumor suppressor $(45,46)$. DMBT1 is highly expressed in normal lung tissues, but is present at low levels in lung cancer cell lines and primary NSCLC tissues (45). In the present study, among patients with primary NSCLC, the responding group exhibited higher levels of DMBT1 compared with those in the non-responding group, whereas increased expression levels of DMBT1 were present in patients with a longer PFS compared with those in patients with a shorter PFS. Although DMBT1 is lowly expressed in patients with NSCLC, its relatively high expression levels may potentially be used as an index for predicting 
A

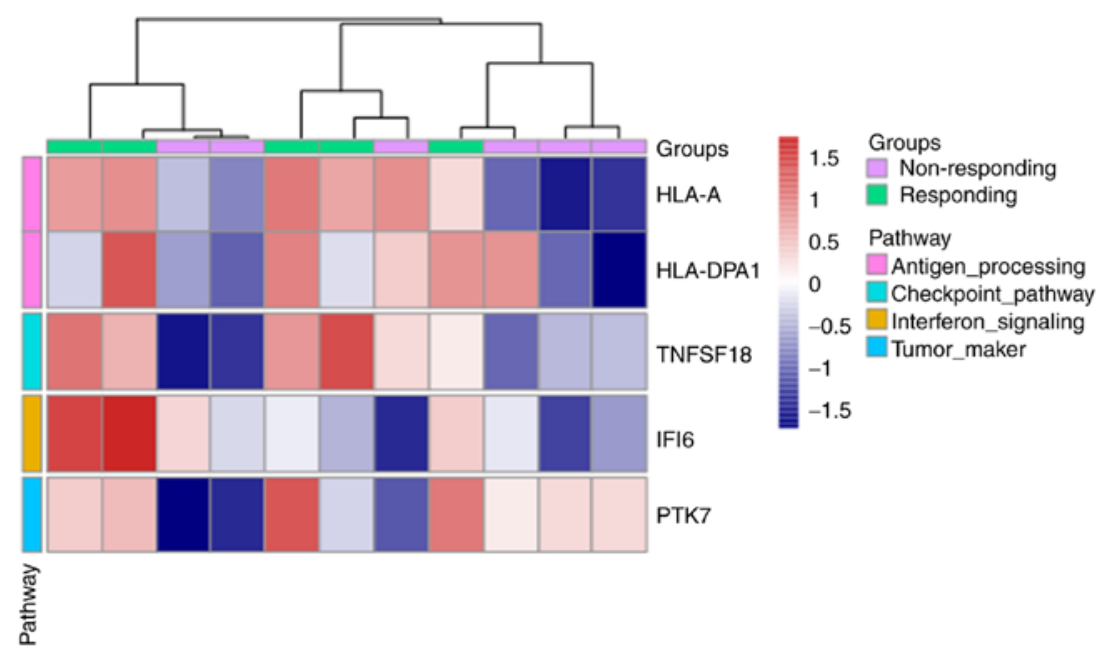

B

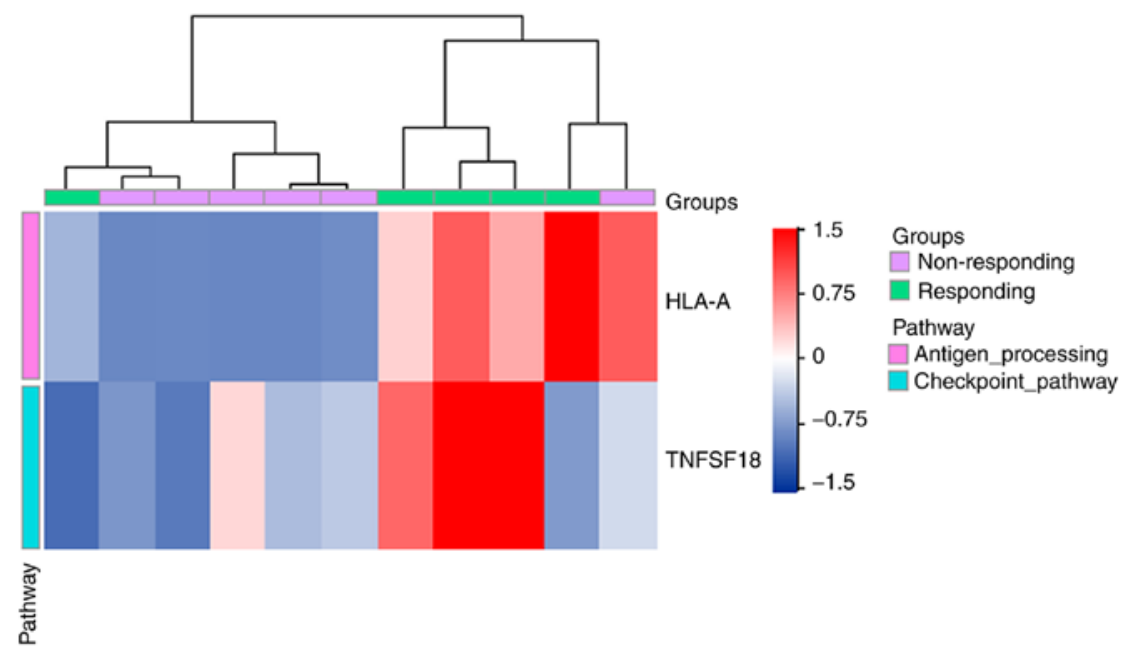

C

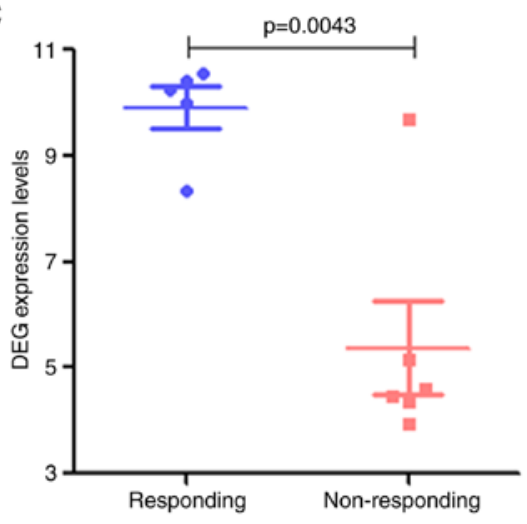

D

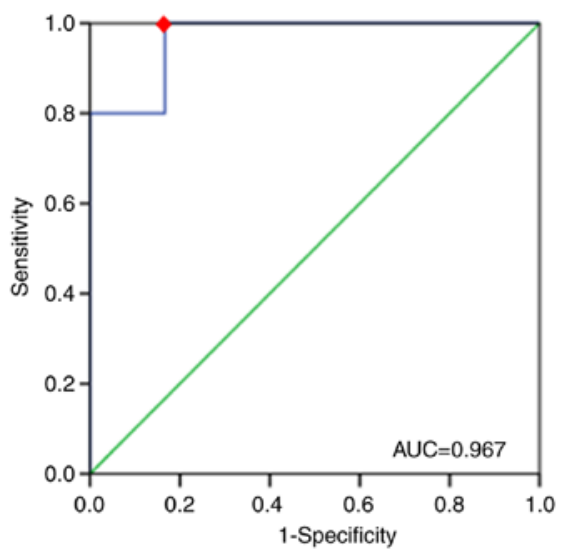

Figure 6. DEG set-based prediction of the efficacy of anti-PD-1 treatment in patients with metastatic NSCLC. (A) Cluster analysis of the five DEGs identified in patients with metastatic NSCLC. (B) Further cluster analysis of the gene set for distinguishing patients with metastatic NSCLC. (C) The expression levels of the DEG set in the responding group were significantly higher compared with those in the non-responding group. (D) Receiver operating characteristic curve was used to predict the efficacy of anti-PD-1 treatment. Patients with a DEG set expression value $>6.741$ benefited from anti-PD-1 therapy. PD-1, programmed death-1; NSCLC, non-small cell lung cancer; DEG, differentially expressed gene; AUC, area under the curve.

the efficacy of anti-PD-1 treatment in patients with primary NSCLC.

Among patients with metastatic NSCLC in the present study, the responding group presented with significantly higher levels of HLA-A and TNFSF18 compared with those in the non-responding group. HLA-A belongs to the HLA class I antigens and serves a crucial role in presenting tumor cell immunogenic polypeptide to $\mathrm{T}$ cells as well as promoting the antitumor effects of cytotoxic $\mathrm{T}$ lymphocytes $(47,48)$. However, HLA-A levels are markedly downregulated in the majority of primary NSCLC tumors and all metastatic lymph nodes compared with those in normal lung tissues (49). 

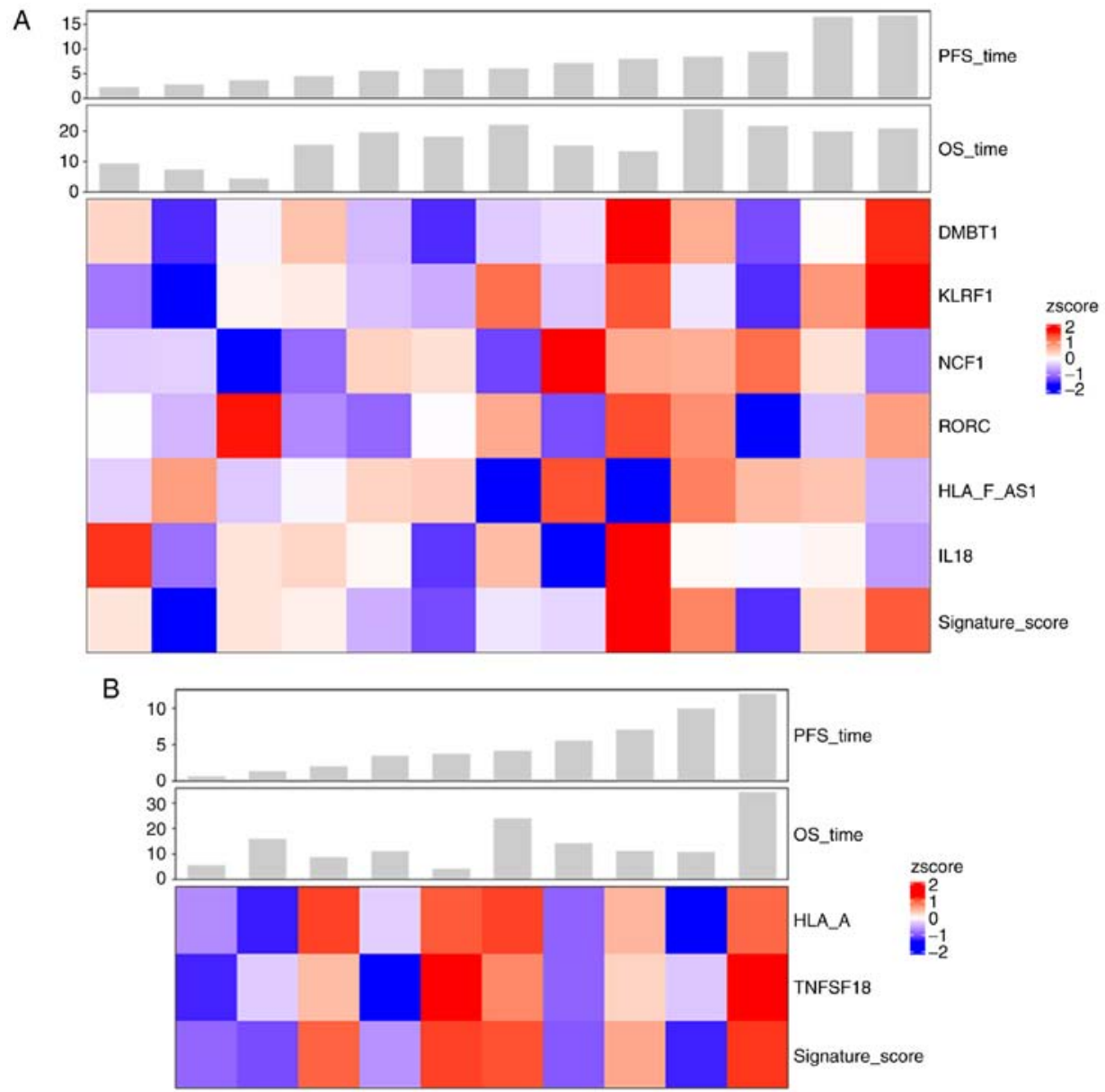

Figure 7. Survival analysis of patients with primary and metastatic carcinoma. (A) Among patients with primary carcinoma, high expression levels of DMBT1, KLRF1, RORC and the 6-gene set were observed in patients with longer PFS. (B) In metastatic carcinoma, patients with a longer PFS displayed high expression levels of HLA-A, TNFSF18 and the 2-gene set. PFS, progression-free survival; OS, overall survival; HLA-F-AS1, HLA-F antisense RNA 1; NCF1, neutrophil cytosolic factor 1; RORC, RAR-related orphan receptor C; DMBT1, deleted in malignant brain tumors 1; KLRF1, killer cell lectin-like receptor F1; IL-18, interleukin-18; HLA-A, major histocompatibility complex class IA; TNFSF18, tumor necrosis factor ligand superfamily member 18.

TNFSF18, also termed glucocorticoid-induced TNFR-related protein (GITRL), participates in the functioning of effector and regulatory $\mathrm{T}$ cells, which is important for the development of immune responses (50). Upregulation of GITRL has been demonstrated to improve antitumor immunity in murine Lewis lung carcinoma $(51,52)$. In addition, in the present study, patients with metastatic NSCLC with a longer PFS presented with higher expression levels of HLA-A and TNFSF18 compared with those in patients with a shorter PFS. Therefore, patients with metastatic NSCLC with high expression levels of HLA-A and TNFSF18 may benefit from anti-PD-1 treatment, suggesting that HLA-A and TNFSF18 may be potential biomarkers for predicting the efficacy of anti-PD-1 therapy in patients with metastatic NSCLC. PTK7 is a member of the receptor protein tyrosine kinase family (53). Studies have demonstrated that PTK7 is highly expressed in tumor tissues of patients with primary lung adenocarcinoma, and inhibition of PTK7 reduces the number of tumor-initiating cells and induces tumor regression $(53,54)$. By contrast, one study has reported that the mRNA and protein expression levels of PTK7 are downregulated in human lung squamous cell carcinoma compared with those in normal lung tissues, and overexpression of PTK7 in lung cancer cells inhibits cell proliferation, invasion and migration (55). Thus, it remains to be determined whether PTK7 is associated with the development of NSCLC or the response to anti-PD-1 treatment.

Single-gene predictive biomarkers are usually considered unsatisfactory in terms of accuracy and precision. In recent years, an increasing number of studies have demonstrated that biomarkers consisting of gene sets (multiple DEGs) are more accurate compared with single-gene biomarkers $(56,57)$. Li et al (58) have established a 4-gene set biomarker that predicts early relapse in advanced epithelial ovarian cancer after initial platinum-paclitaxel chemotherapy with an accuracy $\sim 65.5 \%$. In addition, a minimal driver gene set has been developed to predict bone metastasis in breast cancer (59). Another study has proposed that an immune gene-set based signature may serve as a promising biomarker for estimating overall survival of patients with ovarian cancer (60). The results of the present study demonstrated a gene set comprising six DEGs (HLA-F-AS1, NCF1, RORC, DMBT1, KLRF and IL-18) may be used for predicting the efficacy of anti-PD-1 therapy in patients with primary NSCLC; specifically, patients with a calculated expression level of the DEG set $>6.501$ may benefit from anti-PD-1 therapy. In addition, a DEG set comprising two DEGs (HLA-A and TNFSF18) may be applied to predict the efficacy of anti-PD-1 therapy in patients with metastatic NSCLC. Patients with an expression level of the 
gene set $>6.741$ may benefit from anti-PD-1 monoclonal antibody treatment.

The present study had certain limitations due to the small sample size. In addition, there were no overlapping DEGs or gene sets observed for both primary and metastatic NSCLC in the present study. In two previous studies $(61,62)$, patients with primary and metastatic cancer also exhibited inconsistent gene expression alterations; this problem should be addressed in depth in future studies.

In summary, the present study conducted RNA IO panel sequencing to identify potential biomarkers for predicting the response to anti-PD-1 therapy in patients with primary or metastatic NSCLC. The results of the present study demonstrated that five immune-related DEGs and two DEG sets may be used, respectively, as single and combination biomarkers for the prediction of treatment efficacy. Although these results provided a basis for identification of additional biomarkers to predict the response to anti-PD-1 treatment, they need to be verified in further studies.

\section{Acknowledgements}

Not applicable.

\section{Funding}

No funding was received.

\section{Availability of data and materials}

Datasets used during the present study were not uploaded to public databases in order to protect patient privacy. The datasets are available from the corresponding author on reasonable request.

\section{Authors' contributions}

BC, MY and LL designed the study and performed the experiments. YX, KL and JL collected the data. DR, JZ, LX and FX analyzed the data. YX, DR and JZ drafted the manuscript. LL revised the manuscript critically for important intellectual content. BC and LL confirm the authenticity of all the raw data. All authors read and approved the final manuscript.

\section{Ethics approval and consent to participate}

This study was approved by the Ethics Committee of the Cancer Hospital Affiliated to Xiangya Medical College, Central South University (Changsha, China; approval no. 2019 fast review of scientific research [08]). Informed consents were obtained from all individual participants included in the study.

\section{Patient consent for publication}

Not applicable.

\section{Competing interests}

Two of the authors (DR and JZ) are affiliated with Genecast Biotechnology Co., Ltd., who provided the RNA immune-oncology (IO) profiling panel for the present study. All other authors declare that they have no competing interests.

\section{References}

1. Bray F, Ferlay J, Soerjomataram I, Siegel RL, Torre LA and Jemal A: Global cancer statistics 2018: GLOBOCAN estimates of incidence and mortality worldwide for 36 cancers in 185 countries. CA Cancer J Clin 68: 394-424, 2018.

2. Herbst RS, Morgensztern D and Boshoff C: The biology and management of non-small cell lung cancer. Nature 553: 446-454, 2018.

3. Pisters KM: The role of chemotherapy in early-stage (stage I and II) resectable non-small cell lung cancer. Semin Radiat Oncol 10: 274-279, 2000.

4. Losanno T, Rossi A, Maione P, Napolitano A and Gridelli C: Anti-EGFR and antiangiogenic monoclonal antibodies in metastatic non-small-cell lung cancer. Expert Opin Biol Ther 16: 747-758, 2016.

5. Gridelli C, de Castro Carpeno J, Dingemans AC, Griesinger F, Grossi F,Langer C,Ohe Y,Syrigos K, ThatcherN,Das-Gupta A, et al: Safety and efficacy of bevacizumab plus standard-of-care treatment beyond disease progression in patients with advanced non-small cell lung cancer: The AvaALL randomized clinical trial. JAMA Oncol 4: e183486, 2018.

6. Domagała-Kulawik J: Immune checkpoint inhibitors in non-small cell lung cancer - towards daily practice. Adv Respir Med 86: 142-148, 2018.

7. Horn L, Spigel DR, Vokes EE, Holgado E, Ready N, Steins M, Poddubskaya E, Borghaei H, Felip E, Paz-Ares L, et al: Nivolumab versus docetaxel in previously treated patients with advanced non-small-cell lung cancer: Two-year outcomes from two randomized, open-label, phase III trials (CheckMate 017 and CheckMate 057). J Clin Oncol 35: 3924-3933, 2017.

8. Vokes EE, Ready N, Felip E, Horn L, Burgio MA, Antonia SJ, Arén Frontera O, Gettinger S, Holgado E, Spigel D, et al: Nivolumab versus docetaxel in previously treated advanced non-small-cell lung cancer (CheckMate 017 and CheckMate 057): 3-year update and outcomes in patients with liver metastases. Ann Oncol 29: 959-965, 2018.

9. Herbst RS, Baas P, Kim DW, Felip E, Pérez-Gracia JL, Han JY, Molina J, Kim JH, Arvis CD, Ahn MJ, et al: Pembrolizumab versus docetaxel for previously treated,PD-L1-positive, advanced non-small-cell lung cancer (KEYNOTE-010): A randomised controlled trial. Lancet 387: 1540-1550, 2016

10. Huang M, Pietanza MC, Samkari A, Pellissier J, Burke T, Chandwani S, Kong F and Pickard AS: Q-TWiST analysis to assess benefit-risk of pembrolizumab in patients with PD-L1-positive advanced or metastatic non-small cell lung cancer. Pharmacoeconomics 37: 105-116, 2019.

11. Peters S, Kerr KM and Stahel R: PD-1 blockade in advanced NSCLC: A focus on pembrolizumab. Cancer Treat Rev 62: 39-49, 2018.

12. Dermani FK, Samadi P, Rahmani G, Kohlan AK and Najafi R: PD-1/PD-L1 immune checkpoint: Potential target for cancer therapy. J Cell Physiol 234: 1313-1325, 2019.

13. Brahmer J, Reckamp KL, Baas P, Crinò L, Eberhardt WE, Poddubskaya E, Antonia S, Pluzanski A, Vokes EE, Holgado E, et al: Nivolumab versus docetaxel in advanced squamous-cell non-small-cell lung cancer. N Engl J Med 373: 123-135, 2015.

14. Borghaei H, Paz-Ares L, Horn L, Spigel DR, Steins M, Ready NE, Chow LQ, Vokes EE, Felip E, Holgado E, et al: Nivolumab versus docetaxel in advanced nonsquamous non-small-cell lung cancer. N Engl J Med 373: 1627-1639, 2015.

15. Morgensztern D and Herbst RS: Nivolumab and pembrolizumab for non-small cell lung cancer. Clin Cancer Res 22: 3713-3717, 2016.

16. Shukuya T and Carbone DP: Predictive markers for the efficacy of anti-PD-1/PD-L1 antibodies in lung cancer. J Thorac Oncol 11: 976-988, 2016

17. Hellmann MD, Ciuleanu TE, Pluzanski A, Lee JS, Otterson GA, Audigier-Valette C, Minenza E, Linardou H, Burgers S, Salman $\mathrm{P}$, et al: Nivolumab plus ipilimumab in lung cancer with a high tumor mutational burden. N Engl J Med 378: 2093-2104, 2018.

18. Rizvi NA, Hellmann MD, Snyder A, Kvistborg P, Makarov V, Havel JJ, Lee W, Yuan J, Wong P, Ho TS, et al: Cancer immunology. Mutational landscape determines sensitivity to PD-1 blockade in non-small cell lung cancer. Science 348: 124-128, 2015.

19. Jin Y, Dong H, Xia L, Yang Y, Zhu Y, Shen Y, Zheng H, Yao C, Wang Y and Lu S: The diversity of gut microbiome is associated with favorable responses to anti-programmed death-1 immunotherapy in chinese patients with NSCLC. J Thorac Oncol 14: 1378-1389, 2019.

20. Herbst RS, Soria JC, Kowanetz M, Fine GD, Hamid O, Gordon MS, Sosman JA, McDermott DF, Powderly JD, Gettinger SN, et al: Predictive correlates of response to the anti-PD-L1 antibody MPDL3280A in cancer patients. Nature 515: 563-567, 2014. 
21. Petrosyan F, Daw H, Haddad A, Spiro T and Sood R: Gene expression profiling for early-stage NSCLC. Am J Clin Oncol 38: 103-107, 2015.

22. Li T, Kung HJ, Mack PC and Gandara DR: Genotyping and genomic profiling of non-small-cell lung cancer: Implications for current and future therapies. J Clin Oncol 31: 1039-1049, 2013.

23. Chim SS, Wong KK, Chung CY, Lam SK, Kwok JS, Lai CY, Cheng YK, Hui AS, Meng M, Chan OK, et al: Systematic selection of reference genes for the normalization of circulating RNA transcripts in pregnant women based on RNA-Seq data. Int J Mol Sci 18: 1709, 2017.

24. Kamps R, Brandão RD, van den Bosch BJ, Paulussen AD, Xanthoulea S, Blok MJ, Romano A: Next-generation sequencing in oncology: Genetic diagnosis, risk prediction and cancer classification. Int J Mol Sci 18: 308, 2017.

25. Xu H, Chen X, Lin D, Zhang J, Li C, Zhang D and Zhang X: Conformance assessment of PD-L1 expression between primary tumour and nodal metastases in non-small-cell lung cancer. OncoTargets Ther 12: 11541-11547, 2019.

26. Haragan A, Field JK, Davies MP, Escriu C, Gruver A and Gosney JR: Heterogeneity of PD-L1 expression in non-small cell lung cancer: Implications for specimen sampling in predicting treatment response. Lung Cancer 134: 79-84, 2019.

27. Armato SG III and Nowak AK: Revised modified response evaluation criteria in solid tumors for assessment of response in malignant pleural mesothelioma (version 1.1). J Thorac Oncol 13: 1012-1021, 2018.

28. Cottrell TR, Thompson ED, Forde PM, Stein JE, Duffield AS Anagnostou V, Rekhtman N, Anders RA, Cuda JD, Illei PB, et al: Pathologic features of response to neoadjuvant anti-PD-1 in resected non-small-cell lung carcinoma: A proposal for quantitative immune-related pathologic response criteria (irPRC). Ann Oncol 29: 1853-1860, 2018.

29. Paluch BE, Glenn ST, Conroy JM, Papanicolau-Sengos A, Bshara W, Omilian AR, Brese E, Nesline M, Burgher B, Andreas J, et al: Robust detection of immune transcripts in FFPE samples using targeted RNA sequencing. Oncotarget 8: 3197-3205, 2017.

30. Ritchie ME, Phipson B, Wu D, Hu Y,Law CW, Shi W and Smyth GK: limma powers differential expression analyses for RNA-sequencing and microarray studies. Nucleic Acids Res 43: e47, 2015.

31. R Core Team: R: A language and environment for statistical computing. R Foundation for Statistical Computing, Vienna, Austria. Available from: https://www.R-project.org2018.

32. Yu G, Wang LG, Han Y and He QY: clusterProfiler: An R package for comparing biological themes among gene clusters OMICS 16: 284-287, 2012

33. Hänzelmann S, Castelo R and Guinney J: GSVA: Gene set variation analysis for microarray and RNA-seq data. BMC Bioinformatics 14: 7, 2013.

34. Qu J, Mei Q, Liu L, Cheng T, Wang P, Chen L and Zhou J: The progress and challenge of anti-PD-1/PD-L1 immunotherapy in treating non-small cell lung cancer. Ther Adv Med Oncol: Feb 15, 2021 (Epub ahead of print). doi: 10.1177/1758835921992968.

35. Valecha GK, Vennepureddy A, Ibrahim U, Safa F, Samra B and Atallah JP: Anti-PD-1/PD-L1 antibodies in non-small cell lung cancer: The era of immunotherapy. Expert Rev Anticancer Ther 17: 47-59, 2017.

36. Chen R, Tao Y, Xu X, Shan L, Jiang H, Yin Q, Pei L, Cai F, Ma L and $\mathrm{Yu} Y$ : The efficacy and safety of nivolumab, pembrolizumab, and atezolizumab in treatment of advanced non-small cell lung cancer. Discov Med 26: 155-166, 2018.

37. Rizvi NA, Mazières J, Planchard D, Stinchcombe TE, Dy GK, Antonia SJ, Horn L, Lena H, Minenza E, Mennecier B, et al: Activity and safety of nivolumab, an anti-PD-1 immune checkpoint inhibitor, for patients with advanced, refractory squamous non-small-cell lung cancer (CheckMate 063): A phase 2, single-arm trial. Lancet Oncol 16: 257-265, 2015.

38. Rolfo C,Caglevic C,SantarpiaM, Araujo A,GiovannettiE,GallardoCD, Pauwels P and Mahave M: Immunotherapy in NSCLC: A promising and revolutionary weapon. Adv Exp Med Biol 995: 97-125, 2017.

39. Yi M, Jiao D, Xu H, Liu Q, Zhao W, Han X and Wu K: Biomarkers for predicting efficacy of PD-1/PD-L1 inhibitors. Mol Cancer 17: 129, 2018.

40. Chen G, Huang AC, Zhang W, Zhang G, Wu M, Xu W, Yu Z, Yang J, Wang B, Sun H, et al: Exosomal PD-L1 contributes to immunosuppression and is associated with anti-PD-1 response. Nature 560: 382-386, 2018

41. Chen L and Han X: Anti-PD-1/PD-L1 therapy of human cancer: Past, present, and future. J Clin Invest 125: 3384-3391, 2015.

42. Yang Z, Li H, Wang Z, Yang Y, Niu J, Liu Y, Sun Z and Yin C: Microarray expression profile of long non-coding RNAs in human lung adenocarcinoma. Thorac Cancer 9: 1312-1322, 2018
43. Holmdahl R, Sareila O, Olsson LM, Bäckdahl L and Wing K: Ncf1 polymorphism reveals oxidative regulation of autoimmune chronic inflammation. Immunol Rev 269: 228-247, 2016.

44. Kelkka T, Pizzolla A, Laurila JP, Friman T, Gustafsson R, Källberg E, Olsson O, Leanderson T, Rubin K, Salmi M, et al: Mice lacking NCF1 exhibit reduced growth of implanted melanoma and carcinoma tumors. PLoS One 8: e84148, 2013

45. Wu W, Kemp BL, Proctor ML, Gazdar AF, Minna JD, Hong WK and Mao L: Expression of DMBT1, a candidate tumor suppressor gene, is frequently lost in lung cancer. Cancer Res 59: 1846-1851, 1999.

46. Mollenhauer J, Helmke B, Müller H, Kollender G, Lyer S, Diedrichs L, Holmskov U, Ligtenberg T, Herbertz S, Krebs I, et al: Sequential changes of the DMBT1 expression and location in normal lung tissue and lung carcinomas. Genes Chromosomes Cancer 35: 164-169, 2002.

47. Raez LE, Cassileth PA, Schlesselman JJ, Sridhar K, Padmanabhan S, Fisher EZ, Baldie PA and Podack ER: Allogeneic vaccination with a B7.1 HLA-A gene-modified adenocarcinoma cell line in patients with advanced non-small-cell lung cancer J Clin Oncol 22: 2800-2807, 2004

48. Leclerc M, Mezquita L, Guillebot De Nerville G, Tihy I, Malenica I, Chouaib S and Mami-Chouaib F: Recent advances in lung cancer immunotherapy: Input of T-cell epitopes associated with impaired peptide processing. Front Immunol 10: 1505, 2019.

49. Xiao-Peng H, Fu-Jie S, Xiang-Yan L, Wang Z, Li XX, Liu FY, Chen G, Jiang WP, et al: The relationship between KRAS gene mutations and HLA class I antigen downregulation in the metastasis of non-small cell lung cancer. J Int Med Res 41: 1473-1483, 2013.

50. Nocentini G, Ronchetti S, Petrillo MG and Riccardi C: Pharmacological modulation of GITRL/GITR system: Therapeutic perspectives. Br J Pharmacol 165: 2089-2099, 2012.

51. Tian J, Ma J, Ma K, Ma B, Tang X, Baidoo SE, Tong J, Yan J, $\mathrm{Lu} \mathrm{L}, \mathrm{Xu} \mathrm{H}$, et al: Up-regulation of GITRL on dendritic cells by WGP improves anti-tumor immunity in murine Lewis lung carcinoma. PLoS One 7: e46936, 2012.

52. Ma J, Wang S, Ma B, Mao C, Tong J, Yang M, Wu C, Jiao Z, Lu L and Xu H: Dendritic cells engineered to express GITRL enhance therapeutic immunity in murine Lewis lung carcinoma. Cancer Lett 301: 142-150, 2011

53. Chen R, Khatri P, Mazur PK, Polin M, Zheng Y, Vaka D, Hoang CD, Shrager J, Xu Y, Vicent S, et al: A meta-analysis of lung cancer gene expression identifies PTK7 as a survival gene in lung adenocarcinoma. Cancer Res 74: 2892-2902, 2014.

54. Damelin M, Bankovich A, Bernstein J, Lucas J, Chen L, Williams S, Park A, Aguilar J, Ernstoff E, Charati M, et al: A PTK7-targeted antibody-drug conjugate reduces tumor-initiating cells and induces sustained tumor regressions. Sci Transl Med 9: eaag2611, 2017.

55. Kim JH, Kwon J, Lee HW, Kang MC, Yoon HJ, Lee ST and Park JH: Protein tyrosine kinase 7 plays a tumor suppressor role by inhibiting ERK and AKT phosphorylation in lung cancer. Oncol Rep 31: 2708-2712, 2014.

56. Hughey JJ: Machine learning identifies a compact gene set for monitoring the circadian clock in human blood. Genome Med 9: 19, 2017.

57. Hsu YC, Chiu YC, Chen Y, Hsiao TH and Chuang EY: A simple gene set-based method accurately predicts the synergy of drug pairs. BMC Syst Biol 10 (Suppl 3): 66, 2016.

58. Li N, Hou JL, Shi ZZ, Li XG, Li N, Sun YC, Xu X, Cai Y, Zhang X, Zhang KT, et al: Copy number changes of 4-gene set may predict early relapse in advanced epithelial ovarian cancer after initial platinum-paclitaxel chemotherapy. Am J Cancer Res 4: 285-292, 2014.

59. Li JN, Zhong R and Zhou XH: Prediction of bone metastasis in breast cancer based on minimal driver gene set in gene dependency network. Genes (Basel) 10: 466, 2019.

60. Shen S, Wang G, Zhang R, Zhao Y, Yu H, Wei Y and Chen F: Development and validation of an immune gene-set based prognostic signature in ovarian cancer. EBioMedicine 40: 318-326, 2019.

61. Italiano A, Vandenbos FB, Otto J, Mouroux J, Fontaine D, Marcy PY, Cardot N, Thyss A and Pedeutour F: Comparison of the epidermal growth factor receptor gene and protein in primary non-small-cell-lung cancer and metastatic sites: Implications for treatment with EGFR-inhibitors. Ann Oncol 17: 981-985, 2006.

62. Reinholz MM, Bruzek AK, Visscher DW, Lingle WL, Schroeder MJ, Perez EA and Jenkins RB: Breast cancer and aneusomy 17: Implications for carcinogenesis and therapeutic response. Lancet Oncol 10: 267-277, 2009.

This work is licensed under a Creative Commons Attribution-NonCommercial-NoDerivatives 4.0 International (CC BY-NC-ND 4.0) License. 